\title{
Estudo da utilização de resíduos de construção e demolição em concreto para fins rodoviários
}

A construção civil é uma grande geradora de resíduos que, em sua maioria, são descartados em aterros ou em lugares irregulares, gerando impactos ambientais. A construção sustentável é uma alternativa que busca a prevenção e a diminuição da geração de resíduos reduzindo, reutilizando e reciclando. A reciclagem de Resíduos de Construção e Demolição (RCD) como agregados do concreto para pavimentos pode trazer vantagens econômicas, técnicas e ambientais. $O$ pavimento de concreto tem como vantagem uma durabilidade maior que os demais. Este trabalho buscou investigar os resíduos gerados em obras de construção e demolição na cidade de Porto Nacional (TO) e sua aplicação como agregados miúdos do concreto. A pesquisa objetivou resultados que permitissem a verificação do comportamento do concreto em relação a sua resistência a tração e a compressão quando submetido ao que foi proposto para que assim, se pudesse analisar sua aptidão de utilização para fins rodoviários. Os resíduos de cerâmica foram caracterizados e avaliados quanto ao tipo de material, e os agregados miúdos utilizados definidos no traço, tiveram como percentuais de substituição fixados em 0\%, 3\%, 4,5\% e 6\%. Destarte, por meio dos ensaios que foram executados, realizou-se a verificação da possibilidade de substituições de agregados miúdos naturais por agregados miúdos reciclados cerâmicos nos quais alguns se mostraram viáveis e bastante vantajosos não só pela questão ambiental, mas também no ganho de resistência do material.

Palavras-chave: Reciclagem; Resíduo; Concreto; Pavimentação.

\section{Study of the use of road construction and demolition wastes}

Construction is a large waste generator that is mostly disposed of in landfills or in irregular places, causing environmental impacts. Sustainable construction is an alternative that seeks to prevent and reduce waste generation by reducing, reusing and recycling. Recycling Construction and Demolition Waste (RCD) as aggregates of floor concrete can bring economic, technical and environmental advantages. The concrete floor has a longer durability than the others. This work aimed to investigate the waste generated in construction and demolition works in the city of Porto Nacional (TO) and its application as minute aggregates of concrete. The research aimed at results that allowed the verification of the behavior of the concrete in relation to its tensile strength and compression when submitted to what was proposed so that it could analyze its suitability for road use. The ceramic residues were characterized and evaluated according to the type of material, and the fine aggregates used, defined in the trace, had their replacement percentages set at $0 \%, 3 \%, 4,5 \%$ and $6 \%$. Thus, through the tests that were performed, it was verified the possibility of substitution of natural small aggregates by ceramic recycled small aggregates in which some proved viable and quite advantageous not only for the environmental issue, but also in the resistance gain of the material.

Keywords: Recycling; Residue; Concrete; Paving.

Topic: Engenharia de Transportes

Reviewed anonymously in the process of blind peer.
Received: 14/04/2019

Approved: 15/07/2019
Isabela Gomes Teixeira Prazer

Instituto Tocantinense Presidente Antônio Carlos, Brasil http://lattes.cnpq.br/1620412796603733

isabelagtp@hotmail.com

Flávio Vieira da Silva Júnior

Instituto Tocantinense Presidente Antônio Carlos, Brasil

http://lattes.cnpq.br/2211436659738090

flaviovisiju@gmail.com

\section{Taís Gomes (iD}

Instituto Tocantinense Presidente Antônio Carlos, Brasil http://lattes.cnpq.br/42996247748874461

tais.go3@gamil.com

\section{Referencing this:}

PRAZER, I. G. T.; SILVA JÚNIOR, F. V.; GOMES, T.. Estudo da utilização de resíduos de construção e demolição em concreto para fins rodoviários. Engineering Sciences, v.7, n.2, p.60-68, 2019. DOI: http://doi.org/10.6008/CBPC2318-3055.2019.002.0007 


\section{INTRODUÇÃO}

A geração de resíduos e sua disposição inadequada é uma das principais causas da degradação do meio ambiente que pode afetar na qualidade de vida das pessoas, nos serviços do ecossistema e na disponibilidade de recursos naturais. A construção civil é uma grande consumidora desses recursos, e apesar de ser um setor eminente para a sociedade, também é uma das grandes geradoras de resíduos em que, se não tiver um correto gerenciamento e uma gestão adequada, acaba se tornando parte deste problema e podendo até mesmo representar um grande desperdício econômico (SINDUSCON, 2012).

Os resíduos da construção civil são chamados de resíduos de construção e demolição (RCD), e em muitos casos pode ser composto por materiais suscetível de reaproveitamento e reciclagem. Uma opção de sua reciclagem é como agregados reciclados para concretos, que podem atingir ótimos desempenhos como na fabricação de concretos para blocos de pavimentação.

Existem dois principais tipos de pavimentos rodoviários: os flexíveis, que possuem um custo de execução menor, e os rígidos ou de concreto. Porém, segundo Oliveira (2000), o pavimento de concreto tem como vantagem uma durabilidade maior, podendo funcionar mais de 20 anos sem nenhuma intervenção para reparos ou manutenção.

Portanto, como o pavimento de concreto possui ao longo do tempo um custo-benefício melhor, a associação do dimensionamento do concreto utilizado para ele com a reciclagem de resíduos de construção como agregados, torna-se uma questão importante a ser estudada, podendo trazer mais vantagens econômicas, técnicas e ambientais. Deste modo, o presente trabalho visa realizar um estudo da substituição dos resíduos de construção e demolição como agregado miúdo no concreto, analisando sua influência na resistência a tração e a compressão para que se possa verificar a possibilidade de sua utilização para fins rodoviários.

\section{METODOLOGIA}

Para desenvolver este trabalho, foram recolhidas amostras de RCD em uma obra de Porto Nacional (TO) e encaminhadas para o laboratório do ITPAC-PORTO, onde foi feita a separação, quando necessário, do concreto no material cerâmico, e assim deixando apenas o RCD classificado como agregado reciclado de cerâmica. O material cerâmico foi quebrado com o auxílio de uma marreta e de um soquete para obter um tamanho que passasse na abertura do britador.

As amostras depois de separadas e quebradas foram encaminhadas para moagem e transformadas em agregados miúdos passando primeiramente no britador, depois no equipamento de Abrasão Los Angeles e por fim se fazendo o peneiramento, separando em baldes para uso a porção passante da peneira de 1,2 $\mathrm{mm}$ e que ficava retida na de $600 \mathrm{~mm}$ de acordo com os parâmetros obtidos de ensaios laboratoriais e caracterização para definição da sua granulometria e modulo de finura.

Para realizar o trabalho foram utilizados os seguintes materiais: Agregado miúdo (Areia Grossa); Agregado graúdo (Brita 1); resíduo de construção civil e demolição (Agregados reciclados), cerâmico; 
Cimento Portland composto com escória CPII-E-32; aditivo polifuncional; e Água fornecida pela companhia de abastecimento.

\section{Caracterização dos agregados}

Os ensaios de caracterização dos agregados realizados são: granulometria, massa unitária, massa específica e impurezas orgânicas. O ensaio de granulometria foi realizado de acordo com a ABNT (2003), no qual se consistiu na separação de duas amostras com 500g do agregado cada que depois foram colocadas, separadamente, em um conjunto de peneiras dispostas da maior abertura de malha até a menor e em seguida promoveu-se a agitação mecânica das mesmas. Após isso, foi feito a verificação das massas contidas em cada peneira.

O ensaio de massa unitária foi realizado a partir do registro da massa de um recipiente vazio, com isso o encheu-se com uma pá despejando o agregado a uma distância de $50 \mathrm{~mm}$ da borda superior, finalizando com o nivelamento da superfície e assim verificando a massa do recipiente com o conteúdo, conforme as prescrições da ABNT NBR NM 45.

A determinação da massa especifica foi instruída pela ABNT (2009), onde colocou-se uma amostra $500 \mathrm{~g}$ do agregado no frasco fazendo o registro da massa do conjunto, em seguida enchemos o frasco com água até próxima da marca de $500 \mathrm{ml}$. Foi feito o movimento do mesmo de forma que eliminasse as bolhas de ar para que assim, depois de 1 hora, completa-se com água até a marca de $500 \mathrm{~cm}^{3}$ fazendo a determinação da massa total. A determinação de impurezas orgânicas constituiu-se em colocar uma amostra de $200 \mathrm{~g}$ do agregado em um frasco mais $100 \mathrm{~cm}^{3}$ de hidróxido de sódio, agitando-o vigorosamente, e simultaneamente na preparação da solução padrão em outro frasco, assim como definido na ABNT (2009). Deste modo, após 24 horas de ambos em repouso e em ambiente escuro, foi feito a avaliação comparando o índice de cor de cada.

\section{Caracterização do cimento}

A caracterização do cimento foi realizada em três ensaios: finura, massa específica e tempo de pega. O ensaio de finura do cimento foi feito, perante as determinações da norma DNIT (2004) de seguir as especificações da ABNT (1991), utilizando o emprego da peneira no $200(75 \mu \mathrm{m})$ em que é determinada a porcentagem, em massa, de cimento cujas dimensões de grãos são superiores a $75 \mu m$ (fração retida).

A massa específica do cimento Portland foi verificada na adição de querosene até uma marca entre 0 e $1 \mathrm{~cm}^{3}$ do frasco volumétrico de Le Chetelier, fazendo a leitura inicial na parte inferior e depois foi adicionado 60g de cimento no mesmo, fechando o frasco em seguida como prescrito na ABNT (2017). Com isso, foi realizado o movimento do frasco, cuidadosamente sem criar bolhas, e colocado em uma superfície reta em que, após a decantação total do material, se fez a leitura final.

A determinação do tempo de pega foi feita utilizando, conforme o método da normativa ABNT (2003), o aparelho de Vicat. Os moldes foram enchidos com a pasta de cimento preparada com consistência normal e armazenados em câmara úmida. Após 30 minutos, colocou-se o molde na placa base do aparelho 
situando-o sobre a agulha, fez-se descer a agulha e registrando a leitura inicial. O mesmo procedimento foi feito até se alcançar o fim de pega.

\section{Dosagem}

A dosagem do concreto foi feita com objetivo de obter a resistência a compressão de 30MPa aos 28 dias, com o uso do cimento CPII-E-32, de aditivos para melhoramento de suas propriedades e dosando conforme a necessidade. $\mathrm{O}$ traço do concreto foi elaborado por meio do método de dosagem criado pela Associação Brasileira de Cimento Portland ( $A B C P$ ) no qual a sua resistência média foi determinada por meio do cálculo da resistência de dosagem dada na ABNT NBR 12655 (2015).

\section{Moldagem dos corpos de prova}

A moldagem dos corpos de provas foi feita, incialmente, preparando 6 corpos de prova cilíndricos de Ф10x20cm cujos eram 3 para o ensaio a compressão e 3 para o ensaio de tração, para cada traço nas idades de rompimento de 7 e 28 dias de cura, totalizando no final 48 corpos de prova. Após a preparação dos moldes, realizou-se os traços utilizando o agregado reciclado cerâmico com teores de substituição de $0 \%$ (concreto convencional), 3\%, 4,5\% e 6\% nos agregados miúdo (areia), preparando os concretos de acordo com a ABNT (1996) onde se misturou os materiais secos na ordem de agregado graúdo, agregado miúdo e cimento e depois foi feito a adição da água até criar uma pasta homogênea com o auxílio do aditivo polifuncional.

Rodado o traço, logo em seguida realizou-se o slump test mediante as especificações de sua normativa, ABNT (1998), e alcançada a consistência apropriada, continuou-se fazendo as moldagens dos corpos de provas que consistiu na colocação do concreto nos moldes com o auxílio do vibrador de banana e com a colher de pedreiro fazendo a sua uniformização sem deixar abaixo da borda do molde. Para a cura, após 24 horas da moldagem, os moldes foram colocados no tanque de água com cal até completarem suas idades de 7 ou 28 dias e serem rompidos.

\section{Ensaio de resistência a compressão}

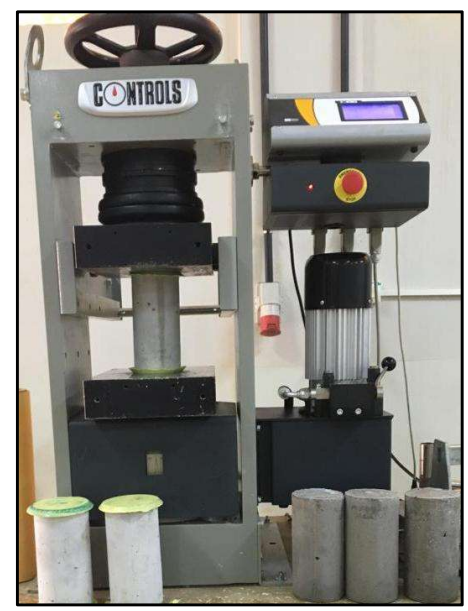

Figura 1: Ensaio de resistência a compressão. 
A resistência a compressão do concreto foi determinada através do ensaio de compressão regido pela ABNT (1996) no qual, para cada idade e tipo de concreto, fez-se o capeamento de 3 corpos de prova e após, alocou-se cada um, rigorosamente centralizados no prato inferior da prensa hidráulica mecânica, conforme a figura 1. Assim, realizou-se o rompimento e a determinação da resistência automaticamente.

\section{Ensaio de resistência a tração do concreto por compressão diametral}

A resistência a tração do concreto foi determinada por compressão diametral conforme as especificações da ABNT (2011). O ensaio consistiu em colocar o corpo-de-prova na prensa hidráulica mecânica, de modo que fique em repouso ao longo de uma geratriz, conforme a figura 2, colocando-o com ajustes entre os pratos e assim, automaticamente a máquina aplicou a carga até a ruptura do corpo de prova, determinando a resistência a tração dele.

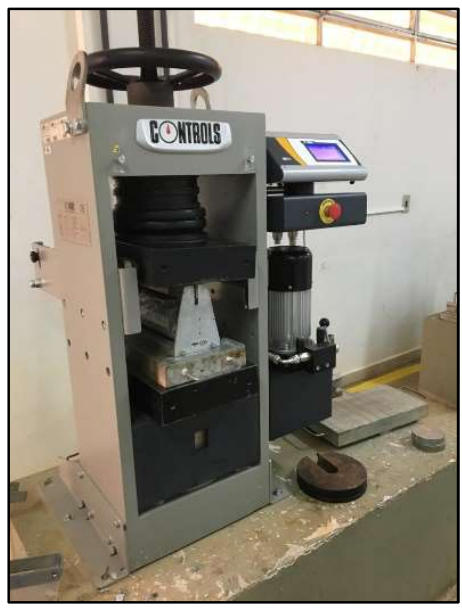

Figura 2: Ensaio de resistência a tração por compressão diametral.

\section{RESULTADOS E DISCUSSÃO}

\section{Caracterização dos agregados}

Os ensaios de caracterização dos agregados realizados obtiveram os resultados apresentados na tabela 1. Os agregados reciclados cerâmicos receberam desagregação manual e mecânica cujo a granulometria escolhida foi a que ficou mais próxima do agregado miúdo natural (areia) como observado na tabela 1.

Tabela 1: Caracterização dos agregados.

\begin{tabular}{|c|c|c|c|c|}
\hline Agregado (Tipo) & $\begin{array}{c}\text { Dimensão Máxima } \\
\text { Característica }\end{array}$ & $\begin{array}{c}\text { Módulo de Finura } \\
\text { (NBR 7217) }\end{array}$ & $\begin{array}{c}\text { Massa Específica } \\
\text { (NBR NM 52) }\end{array}$ & $\begin{array}{c}\text { Massa Unitária } \\
\text { (NBR NM 45) }\end{array}$ \\
\hline Areia & $4,8 \mathrm{~mm}$ & 3,20 & $2,62 \mathrm{~g} / \mathrm{cm}^{3}$ & $1,58 \mathrm{~kg} / \mathrm{dm}^{3}$ \\
\hline Brita & $19 \mathrm{~mm}$ & 7,09 & $2,70 \mathrm{~g} / \mathrm{cm}^{3}$ & $1,62 \mathrm{~kg} / \mathrm{dm}^{3}$ \\
\hline Agregado Miúdo Reciclado Cerâmico & $4,8 \mathrm{~mm}$ & 3,57 & $2,16 \mathrm{~g} / \mathrm{cm}^{3}$ & $1,58 \mathrm{~kg} / \mathrm{dm}^{3}$ \\
\hline
\end{tabular}

O ensaio de impurezas orgânicas foi executado para avaliar a presença de impurezas orgânicas na areia utilizada na confecção dos corpos de prova do concreto. Pode-se verificar que o agregado miúdo analisado estava livre de impurezas, podendo se observar na figura 3 que a primeira solução com areia apresenta cor mais clara que a solução padrão ao findo do tempo do de repouso deles. 


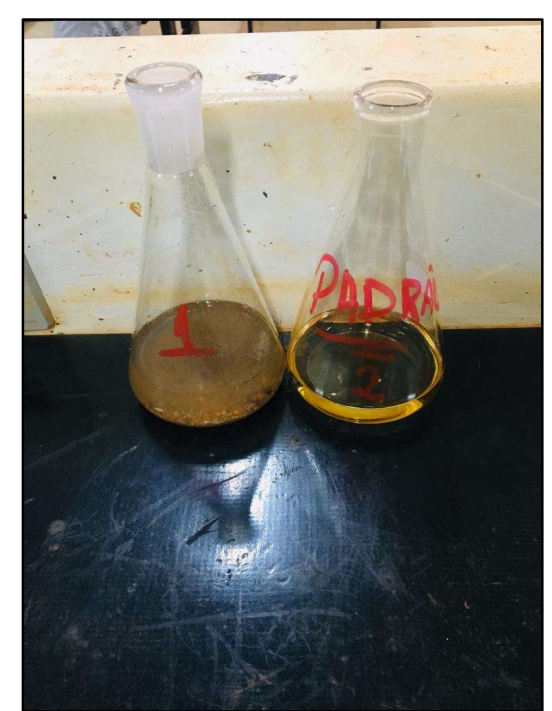

Figura 3: Resultado do ensaio de impurezas orgânicas na areia.

\section{Caracterização do cimento}

Os ensaios de caracterização do cimento realizados têm como resultados os mostrados na tabela 2, onde as determinações obtidas pelo ensaio de tempo de pega estão aparentadas como início de pega e fim de pega. $O$ traço para o concreto foi desenvolvido conforme os dados da tabela 3 , onde também é dado sua definição.

Tabela 2: Caracterização física do cimento CPII-E-32.

\begin{tabular}{|c|c|c|c|c|}
\hline $\begin{array}{c}\text { Características } \\
\text { Físicas }\end{array}$ & $\begin{array}{c}\text { Finura (NBR } \\
\mathbf{1 1 5 7 9 )}\end{array}$ & $\begin{array}{c}\text { Massa Específica (NBR NM } \\
\text { 23) }\end{array}$ & $\begin{array}{c}\text { Início de Pega (NBR NM } \\
\text { 65) }\end{array}$ & $\begin{array}{c}\text { Fim de Pega (NBR NM } \\
\text { 65) }\end{array}$ \\
\hline CPII-E-32 & 0,064 & $3100 \mathrm{~kg} / \mathrm{m}^{3}$ & 2 horas & 4 horas e 5 minutos \\
\hline
\end{tabular}

Tabela 3: Resultados da dosagem experimental.

\begin{tabular}{|c|c|c|c|}
\hline Relação Água Cimento (a/c) & $\begin{array}{c}\text { Abatimento } \\
(\mathbf{m m})\end{array}$ & Resistência a Compressão aos 28 dias (MPa) & Traço Cimento: Areia: Brita: (a/c) \\
\hline 0,4 & $60 \pm 10 \mathrm{~mm}$ & 36,6 & $1: 5,94: 2,09: 0,4$ \\
\hline
\end{tabular}

A pesquisa fez o uso das porcentagens de substituição de $0 \%, 3 \%, 4,5 \%$ e $6 \%$ do agregado miúdo natural (areia) pelo agregado miúdo reciclado cerâmico nesse traço como mostrado na tabela 4. São teores de substituição com porcentagens baixas que foram escolhidos devido a demanda de RCD gerada no Brasil, pois, segundo a ABRELPE (2017), o país apresenta uma geração de resíduos sólidos urbanos em um total de 123.421 toneladas por dia e se adotassem porcentagens elevadas, em grande escala, não haveria resíduo suficiente para execução de quilômetros de pavimentos de concreto.

Tabela 4: Teores de substituição dos traços.

\begin{tabular}{|c|c|c|c|}
\hline Traço & Areia & Brita & Agregado Miúdo Reciclado Cerâmico \\
\hline TCconv. & $100 \%$ & $100 \%$ & $0 \%$ \\
\hline TC3 & $97 \%$ & $100 \%$ & $3 \%$ \\
\hline TC4,5 & $95,5 \%$ & $100 \%$ & $4,5 \%$ \\
\hline TC6 & $94 \%$ & $100 \%$ & $6 \%$ \\
\hline
\end{tabular}




\section{Resistência à compressão}

As figuras 4 e 5 fazem o demonstrativo das resistências à compressão alcançados aos 7 e 28 dias, respectivamente. Pode-se observar que não houve diminuição significativa das resistências a compressão, de ambas idades, entre o concreto convencional (substituição de $0 \%$ ) e os concretos com substituição do agregado miúdo natural pelo agregado miúdo reciclado.

Nenhuma das resistências ficaram abaixo da resistência desejada de $30 \mathrm{MPa}$, mostrado na figura 5 . Vale ressaltar ainda que o concreto com 4,5\% e com $6 \%$ de substituição aos 28 dias demonstraram um aumento bem relevante de resistência, com $37,68 \mathrm{MPa}$ e $34,11 \mathrm{Mpa}$, respectivamente, em relação a do concreto convencional (0\%), com resistência de 31,71MPa.

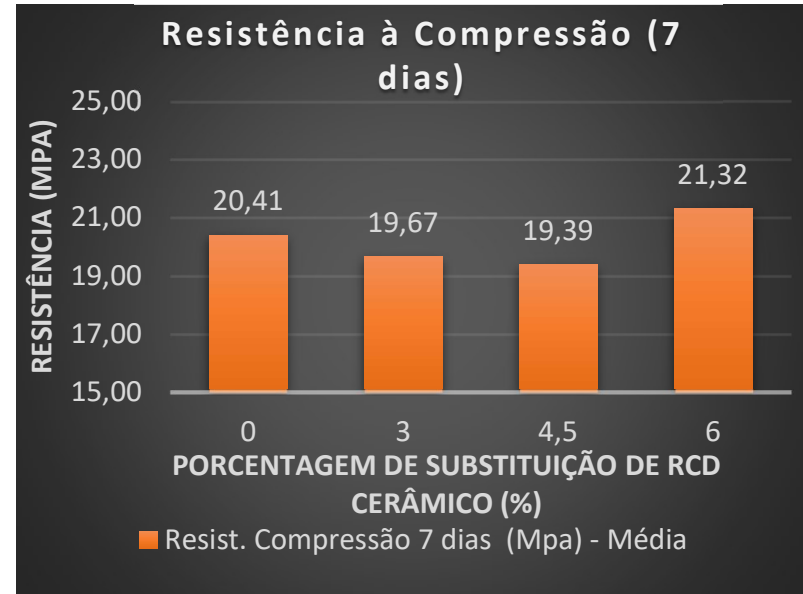

Figura 4: Gráfico das Resistências a Compressão aos 7 dias.

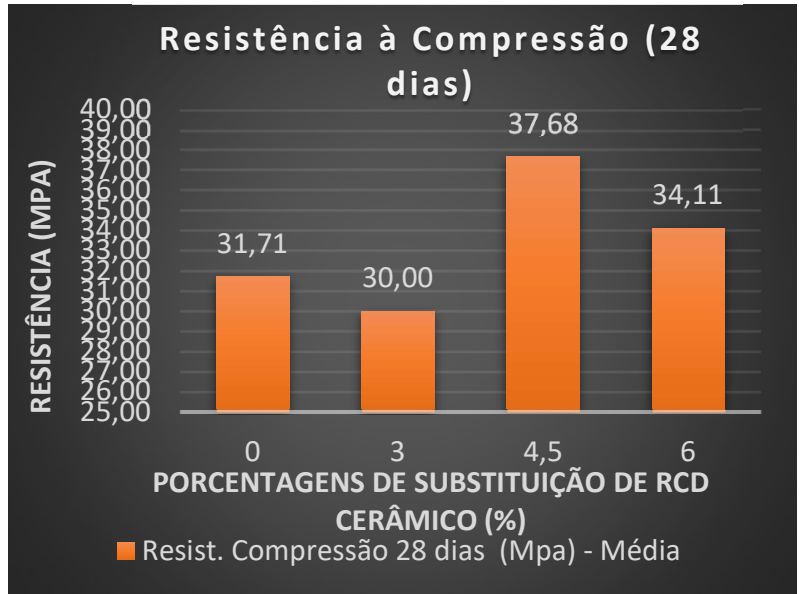

Figura 5: Gráfico das Resistências a Compressão aos 28 dias.

\section{Resistência à tração}

As resistências a tração atingidas nas porcentagens de substituição de $0,3,4,5$ e $6 \%$ são de, respectivamente, 2,28, 2,18, 4,12 e 3,09 MPa, aos 7 dias, e de 4,53, 3,96, 5,34 e 5,76 MPa, aos 28 dias, como demonstradas nas figuras 6 e 7. 0 concreto com 3\% de substituição apresentou certa redução da resistência baseando-se no concreto convencional, e que por ter sido baixa, torna-se insignificante tornando-se possível sua utilização e agregando valores de sustentabilidade na execução dos pavimentos, deste modo, contribuindo para redução dos impactos ambientais gerados pelos resíduos.

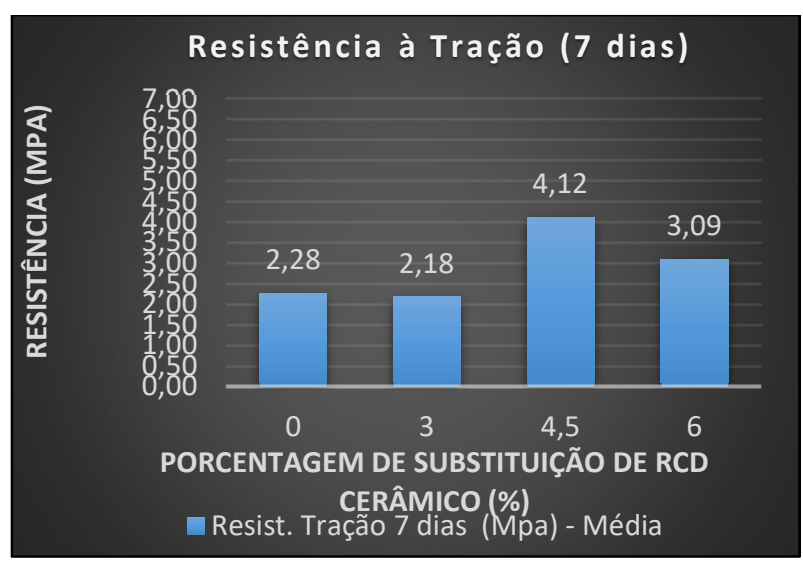

Figura 6: Gráfico das Resistências a Tração aos 7 dias.

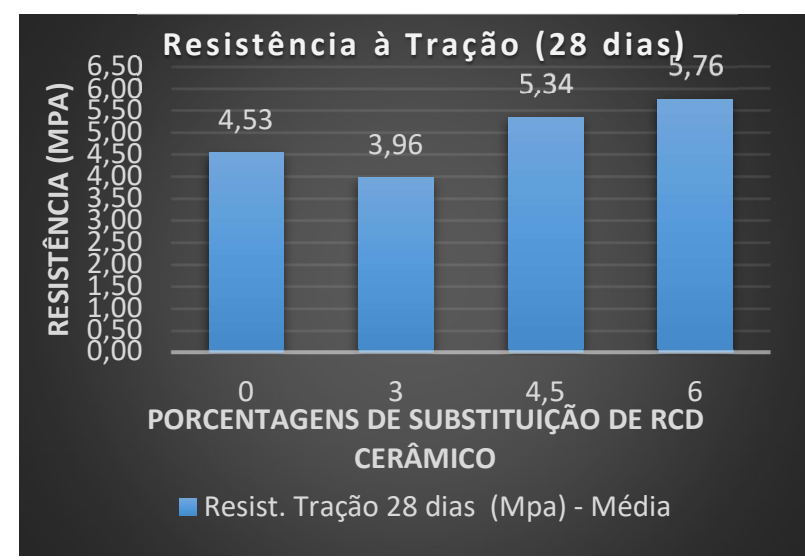

Figura 7: Gráfico das Resistências a Tração aos 28 dias. 
Como se sabe, a resistência predominante do concreto é a compressão e que ele possui baixas resistências a tração tornando eminente sua observação e a necessidade de um rigoroso controle tecnológico para que exerçam sua função de forma satisfatória quando usados em pavimentos. Desta forma, podemos observar nas figuras que alguns teores de substituição obtiveram um aumento bastante significativo da resistência a tração em relação ao concreto com 0\% de RCD.

Os concretos com substituições de 4,5\% e $6 \%$ aos 28 dias se destacaram na predominância de um grande ganho de resistência em relação ao concreto convencional, tornando bastante vantajoso a adoção da utilização deles para fins rodoviários. A resistência à tração do concreto estudado é um parâmetro fundamental para a pesquisa, dado que, de acordo com Pitta (1989, citado por SEVERI, 1997), um pavimento de concreto necessita grandes resistências a tração na flexão e à compressão simples por sofrer grande intensidade de ações mecânicas geradas pelas cargas de tráfegos e pelos efeitos ambientais.

\section{CONCLUSÕES}

O presente estudo, inicialmente, avaliou como necessário a realização da caracterização das amostras de RCD utilizadas visto que o mesmo será avaliado para substituir parte do agregado miúdo natural usado na fabricação do concreto para pavimentos, cuja norma DNIT (2004) prescreve que se deve realizar ensaios de caracterização de todos os materiais usados no traços do concreto para pavimentos rígido. O RCD cerâmico teve sua granulometria modificada e, devido sua heterogeneidade, foi fixado as características que ficasse mais próxima ao do agregado miúdo que foi substituído e assim se obteve 3,57 de módulo de finura, $2,16 \mathrm{~g} / \mathrm{cm}^{3}$ de massa específica e $1,58 \mathrm{~kg} / \mathrm{dm}^{3}$ de massa unitária.

O concreto é um material em que se obtém elevadas resistências a compressão e baixas resistências a tração tornando fundamental a criteriosa observação desta última. O concreto convencional teve resistência a compressão de $31,71 \mathrm{MPa}$ aos 28 dias e, fazendo o comparativo, somente o concreto com teor de substituição de $3 \%$ sofreu redução de resistência a compressão, ficando com $30 \mathrm{MPa}$, no qual essa diferença se torna desprezível. Já os com substituição de 4,5\% e 6\% resultaram em ganho dessa resistência, ficando com, respectivamente, 37,68MPa e 34,11MPa.

A resistência a tração foi devidamente analisada e apresentou excelentes resultados. O concreto convencional resistiu 4,53MPa a tração aos 28 dias e os com substituição de $3 \%, 4,5 \%$ e $6 \%$ resistiram, respectivamente, $3,96 \mathrm{MPa}, 5,34 \mathrm{MPa}$ e 5,76MPa os quais, aos relacioná-los com o convencional, pode-se observar que apenas a primeira obteve uma pequena perda de resistência considerada irrelevante, e que houve o aumento bastante significativo das duas últimas porcentagens.

Deste modo, com as considerações feitas e com os resultados obtidos, o trabalho alcançou seu êxito mostrando que é viável a utilização de RCD cerâmico como agregado reciclado miúdo no concreto garantindo o reaproveitamento de um resíduo que provavelmente seria descartado de modo irregular e que demoraria anos pra se decompor pregando assim a construção sustentável ajudando a reduzir os impactos ambientais. Vale ainda ressaltar que concretos com $4,5 \%$ e $6 \%$ de substituição se destacaram, pois, além da sustentabilidade, foi possível verificar um elevado ganho de resistência gerado pelos mesmos, critério 
eminente principalmente na questão da tração, visto que ela é bastante baixa nos concretos e bastante solicitada nos pavimentos.

Para futuros estudos, sugere-se o desenvolvimento de um número mais expressivo de amostras, afim de se obter resultados mais abrangentes, buscar compreender o que gera o ganho de resistência e verificar o comportamento dos demais resíduos (RCD de concreto e RCD misturado com o cerâmico e concreto) no concreto fazendo o comparativo de qual tem melhor reação.

\section{REFERÊNCIAS}

ABNT. Associação Brasileira de Normas Técnicas. NBR 11579: Cimento Portland: Determinação da finura por meio da peneira $75 \mu \mathrm{m}$ ( $\left.\mathrm{n}^{\circ} 200\right)$ : Método de ensaio. Rio de Janeiro: 1991.

ABNT. Associação Brasileira de Normas Técnicas. NBR 12655: Concreto de cimento Portland: Preparo, controle, recebimento e aceitação: Procedimento. Rio de Janeiro: ABNT, 2015.

ABNT. Associação Brasileira de Normas Técnicas. NBR 16605: Cimento Portland e outros materiais em pó: Determinação da massa específica. Rio de Janeiro: ABNT, 2017.

ABNT. Associação Brasileira de Normas Técnicas. NBR 7215: Cimento Portland: Determinação da resistência à compressão. Rio de Janeiro: ABNT, 1996.

ABNT. Associação Brasileira de Normas Técnicas. NBR 7222: Concreto e argamassa: Determinação da resistência à tração por compressão diametral de corpos de prova cilíndricos. Rio de Janeiro: ABNT, 2011.

ABNT. Associação Brasileira de Normas Técnicas. NBR NM 248: Agregados: Determinação da composição granulométrica. Rio de Janeiro: ABNT, 2003.

ABNT. Associação Brasileira de Normas Técnicas. NBR NM 45: Agregados: Determinação da massa unitária e do volume de vazios. Rio de Janeiro: ABNT, 2006.

ABNT. Associação Brasileira de Normas Técnicas. NBR NM 49: Agregado miúdo: Determinação de impurezas orgânicas. Rio de Janeiro: ABNT, 2001.
ABNT. Associação Brasileira de Normas Técnicas. NBR NM 52: Agregado miúdo: Determinação da massa específica e massa específica aparente. Rio de Janeiro: ABNT, 2009.

ABNT. Associação Brasileira de Normas Técnicas. NBR NM 65: Cimento Portland: Determinação do tempo de pega. Rio de Janeiro: ABNT, 2003.

ABNT. Associação Brasileira de Normas Técnicas. NBR NM 67: Concreto: Determinação da consistência pelo abatimento do tronco de cone. Rio de Janeiro: ABNT, 1998.

ABRELPE. Associação Brasileira de Empresas de Limpeza Pública e Resíduos Especiais. Panorama dos resíduos sólidos no Brasil 2017. São Paulo: ABRELPE, 2017.

DNIT. Departamento Nacional de Infraestrutura de Transportes. NORMA DNIT 054: Pavimento rígido: Estudos de traços de concreto e ensaios de caracterização de materiais: Procedimento. Rio de Janeiro: DNIT, 2004.

OLIVEIRA, P. L.. Projeto estrutural de pavimentos rodoviários e de pisos industriais de concreto. Dissertação (Mestrado em Engenharia Civil) - Universidade de São Paulo, São Carlos, 2000.

SEVERI, A. A.. Considerações sobre os custos de pavimentos rígidos com base em conceitos de gerência de pavimentos. Dissertação (Mestrado em Engenharia Civil) - Universidade de São Paulo, São Carlos, 1997.

SINDUSCON. Sindicatos da Indústria da Construção Civil do Estado de São Paulo Resíduos da construção civil e o estado de São Paulo. São Paulo: SINDUSCON, 2012.

A CBPC - Companhia Brasileira de Produção Científica (CNPJ: 11.221.422/0001-03) detém os direitos materiais desta publicação. Os direitos referem-se à publicação do trabalho em qualquer parte do mundo, incluindo os direitos às renovações, expansões e disseminações da contribuição, bem como outros direitos subsidiários. Todos os trabalhos publicados eletronicamente poderão posteriormente ser publicados em coletâneas impressas sob coordenação da Sustenere Publishing, da Companhia Brasileira de Produção Científica e seus parceiros autorizados. Os (as) autores (as) preservam os direitos autorais, mas não têm permissão para a publicação da contribuição em outro meio, impresso ou digital, em português ou em tradução. 